\title{
Towards the identification of the threshold concepts in parkour - A case study
}

Coolkens Rosalie ${ }^{1}$, Vanhole Nicolas $^{2}, \&$ Cloes Marc $^{3}$

${ }^{1}$ PXL University of Applied Sciences and Arts, Belgium

${ }^{2}$ Parkour influencer, Belgium

${ }^{3}$ University of Liege, Belgium

\section{Context}

Belgium is a federal state consisting of three communities and three regions. The three communities are the Flemish community, the French community, and the German community. The three regions are Flanders, Wallonia, and Brussels-Capital. The Flemish, French and German speaking communities each have their own educational government. Education (o.a. physical education) is compulsory between the ages of 6 and 18 or until one graduates from secondary school. Pre-primary education is available for children from 2.5 to 6 years and although it is not mandatory, almost all children are enrolled. University colleges provide teacher education through a three-year professional bachelor (i.e., undergraduate) programme. Teachers holding their professional bachelor's degree in physical education (PE) can teach this subject in primary school (i.e., ages 2.5-12) and in all first two stages of secondary school (i.e., ages 12-16). They can also teach in the third stage of secondary school (i.e., ages 16-18) but only in vocational education. In Flanders, there are 13 university colleges offering a Physical Education Teacher Education (PETE) programme. Their curriculum consists of 180 ECTS and next to PE, students choose another school subject (e.g., history, biology, French) or a component called 'recreational movement'. This component prepares students in sports and physical activity in non-school settings. PETE educators at university colleges are not expected to hold a $\mathrm{PhD}$. At a university college programme, all three Flemish universities will organize an Educational Master (i.e., graduate) programme. Educational Master programmes in PE prepare students for teaching in the third stage of secondary education and at university colleges. However, it is also possible to teach PE in primary schools and in stages 1 and 2 of secondary education. More information can be found in some publications (De Knop, Theeboom, Huts, De Martelaer, \& Cloes, 2005; De Martelaer, Seghers, Cardon, Haerens, De Boever, \& Cloes, 2014; Iserbyt \& Coolkens, 2019). 


\section{Background}

\section{Rosalie Coolkens}

\section{$\underline{\text { Rosalie.coolkens@pxl.be }}$}

Rosalie Coolkens is a physical education teacher educator at the University College PXL, Department of Education in Hasselt, Belgium. In October 2018, she finished her $\mathrm{PhD}$ theses titled Generalization from physical education to organized and supervised recess in elementary school. Her research focuses primarily on investigating how PE can contribute in the development of a physically active lifestyle.

\section{Nicolas Vanhole}

\section{Nicolas.vanhole@,hotmail.com}

Nicolas Vanhole studied physical education teacher and is a performer and teacher in parkour at the Circus school in Leuven, Belgium. Since 2006, he is practicing parkour at the highest international level. Nicolas works also as a parkour expert in a television program for children.

\section{Marc Cloes}

\section{Marc.Cloes@uliege.be}

Marc Cloes is an honorary full professor in sport pedagogy. He spent his career in the Department of Sport and Rehabilitation Sciences at the University of Liège (Belgium) where he was in charge of the specific part of the physical education teacher education. His scientific activity focuses on sport pedagogy. His research is based on the integrative model of the teaching-learning process, which advocates an ecological approach to the educational relationship. His centers of interest are characterized by a great transversality in the contexts of physical and sports activities. 


\section{Introduction: Parkour as physical activity area within Belgium}

The following case study aims to illustrate sets of threshold concepts within the context of parkour. We selected parkour because of its characteristics and the growing interest in the "fun culture" described in 1995 by the French sport sociologist, Alain Loret. He demonstrated that, during the Eighties, the traditional sports were confronted to the development of new sporting motivations, which established new relationships with the body and nature. Far from the stadiums, those who want to be or claim to be sporting claim the right to surpass themselves, to excess, but also, more simply, to play, have pleasure, and feel conviviality. Sport practice evolved to two cultures. On one hand, the practices inscribed in a "digital culture" take place in domesticated and standardized sites characterized by norms, which make possible to establish hierarchical distinctions between competitors. On the other hand, so-called "analogic" practices occupy the natural or urban ecosystem, without respecting the regulations, responding to the "fun culture".

Parkour is an individual activity in which a person tries to overcome various obstacles by means of swings, jumping, climbing and running (Coolkens, Ward, Seghers \& Iserbyt, 2018). Someone who practices such activity is a 'traceur' (French origin). More PE teachers in Belgium prefer parkour above gymnastics to develop motor competencies. In both Flanders and Wallonia, the government define standards to develop motor competencies as, a healthy and safe lifestyle, social skills as well as positive self-concept. The government does not prescribe content domains. The PE teacher could choose to use parkour, gymnastics or other content domains to reach the standards. In general, the purpose of PE is to develop basic movement skills, which enables children to successfully function within the society and to prepare children for active participation in the movement culture. Whilst parkour has become a popular sport in Belgium, it is still a relative new activity within the PE curriculum. In general, the purpose of the PE curriculum is to develop basic movement skills which enables children to successfully function within the society and to prepare children for active participation in the movement culture. As in primary schools, the secondary school PE curriculum aims at facilitating the adoption of a physically active lifestyle (Council for Qualifications and Curriculum, 2009). The time allocation for PE is 100 minutes per week and lessons are delivered by PE specialists. However, through our collective experiences, we believe because parkour is a lifestyle sport accessible for both sexes and matches people's leisure-sport tastes (Green, 2016) it has a positive contribution to play within PE and nurturing young people to lifelong physical activity. 
All three authors have a certain expertise in parkour. Rosalie Coolkens used parkour as a physical activity area during all her research (Coolkens, Ward, Seghers, \& Iserbyt, 2018). She followed an initiator course parkour run by GymFed, the flemisch Gymnastic Federation in 2014 where she met Nicolas Vanhole, expert in teaching and practicing parkour. Together with Nicolas Vanhole she developed a book Parkour Primitives (Coolkens, Van Oost, Vanhole \& Iserbyt, 2018). This book provides a practical guide for teaching parkour at school and/or leisure context. On a regular basis, she gives workshops focusing on parkour for elementary and secondary pre- and in-service teachers. Nicolas Vanhole is one of the first practitioners of parkour in Belgium. He was a gymnast and discovered parkour by watching the movie 'Yamakasi' together with clips from David Belle, the founder of parkour. In 2006, he started imitating parkour moves with some friends in his neighborhood. He described this situation, as 'the moment when it all started, a beginning of a nice parkour story'. Until now, he is one of the best parkour practitioners and teachers we have in Belgium. Marc Cloes never practiced parkour itself but he considers that if parkour would have existed when he was an adolescent, it would have been his sport. In fact, in the seventies, he has been attracted by the Natural Method (Hébert, 1974) and some forms of the parcours du combattant proposed in PE lessons. During his free time, he played outdoor, climbing regularly on natural obstacles and jumping from one to another one. This gave him some facilities to practice gymnastics during his PE studies. During the first decade of the $21^{\text {st }}$ century, he enjoyed discovering the creation of groups training in this new discipline that is parkour. The gradual introduction of the latter in initial and in-service PETE has been a source of pleasure for him and he has favored it in the courses for which he was responsible at the University of Liege. He is deeply convinced that the practice of parkour is accessible to all and allows young people to experience extraordinary sensations by allowing them to flirt with their limits and enrich their motor skills in a natural way. We all have other biographies that shaped our beliefs and thoughts on Parkour. For Rosalie, parkour is an ideal content domain in PE since everyone can move on their own ability level. It allows for differentiation, there is nothing like wrong or right, it has a great opportunity for a transfer of physical activity outside the PE class and the sport exists of fundamental motor skills (o.a. locomotor activities such as jumping, running, climbing) necessary to adopt a physically active lifestyle. For Nicolas, parkour is a way of life. It is not only a sport that he discovers, it is his profession, it is his leisure activity. For Marc, parkour represents memories of adolescence when he spent hours playing in nature with friends, climbing in trees, jumping from one branch to another one or experiencing obstacle races during PE lessons. These 
personal experiences influenced certainly his professional vision of the importance of the discovery of the natural environment for children motor development.

In the reminder of this chapter we will discuss (1) the identification of the socialization elements that contributed to the career of the expert as practitioner than teacher; (2) The analysis of the variables that are considered as key elements for an effective practice in parkour; (3) The description of the teaching principles and their relationships with learners' involvement and (4) The implications for the identification of threshold concepts.

\section{Analytical concepts}

Our understanding of the Threshold Concepts within parkour has been informed through our engagement with the socio-ecological approach (Cloes \& Roy, 2010). This approach is often used in health behavior research suggesting that human behavior results from an interaction between environmental, individual and interpersonal factors. A socio-ecological model emphasizes the importance for interventions to target several levels of influence simultaneously to change an individual's behavior. In drawing upon these principles, we consider that 'being in the zone or teaching to get in the zone' always take place in the context of a complex culture (Sallis et al., 2006). It is the combination of individual, environmental and policy influences to achieve changes in certain behavior. As a 'new sport', representations that people have about Parkour are influenced by their own contacts with that specific activity with less normative influence from the society than traditional sports.

\section{Using Design Thinking}

To explore threshold concepts in parkour, Rosalie Coolkens and Marc Cloes began by identifying an expert involved in the practice and teaching of the activity. Based on her professional background, Rosalie proposed to meet Nicolas Vanhole. As illustrated by his biography, Nicolas has been involved in several projects that both of them implemented during the last 10 years and he corresponded perfectly to the requested profile.

After receiving Nicolas' agreement for an interview, the two academics discussed possible core concepts necessary 'to be in the zone' (practitioner perspective) or 'to bring someone in the zone' (teacher perspective) during parkour. The two sport pedagogy specialists prepared a semi 
structured interview guide identifying a list of topics to be covered. Two main parts were planned: (1) Questions for expert teacher in parkour (Background information; Information about teaching parkour); (2) Questions for parkour practitioner (Background information; Information about doing parkour). This information seemed necessary to understand the students' learning needs when practicing parkour. Even if the expert's history began by practicing parkour before becoming a specialist teacher, we opted for starting the interview with questions focusing on the teaching expertise. Such choice laid on the assumption that one should avoid to influence the teacher's representations on the notion of flow and focus his attention on the sensations perceived during practice.

The interview lasted 1.5 hour and was recorded and transcribed verbatim with a digital dictaphone. Both academics intervened freely, according to the responses of Nicolas. The sport pedagogy specialists separately selected key concepts through the answers of the practitioner and shared their analysis to begin identifying some Threshold Concepts. In the next section of the paper, we will develop four main topics: (1) The identification of the socialization elements that contributed to the career of the expert as practitioner than teacher; (2) The analysis of the variables that are considered as key elements for an effective practice in parkour; (3) The description of the teaching principles and their relationships with learners' involvement; (4) The implications for the identification of threshold concepts.

\section{Discussion: Outlining the generation of Threshold Concepts in Parkour}

\section{Socialization elements that contributed to the career of the expert}

During the interview, we explored some components from all layers of to the socio-ecological model (Sallis et al., 2006) that influenced his choice at the age of 16 to start with parkour: media (movie and online clips), neighbors, possibility to choose the hours when he wanted to train on a voluntary basis, activity looking cool, support of the parents etc. Nicolas seemed to have natural predispositions for acrobatic activities. When he was a child, he practiced judo and was always trying to do some flips everywhere. His mother imposed him to begin gymnastics. Nicolas started to practice parkour when doing gymnastics since several years. It was during a week internship for gymnastic training organized in another club: “... we saw a movie, a French movie: 'Yamakasi'. I think a lot of people discovered parkour through Yamakasi. So, I saw the movie and I was like, oh it's really cool. It's like gymnastics but even cooler." (Interview - 
0:10:51). This illustrates the impact of media, parents, sports club and Nicolas' natural predisposition for acrobatic activities.

Interestingly, Nicolas did not begin parkour immediately but after watching online video clips of David Belle: "I think I saw the movie when I was eleven and I saw the clips when I was fifteen ... It was on a Sunday afternoon after gymnastics training ... I proposed my friends, ... We saw clips online and we try to imitate all those moves in a small playground." (Interview - 0:11:31). One interesting thing is that that experience was lived with close friends: "Just my really good friends of school ... a lot of people who I still see weekly..." (Interview - 0:13:46). Moreover, proximity of an appropriate place played a role: "We were only living a minute by bike from my place so it takes a kilometer and let's go jump on the streets." (Interview - 0:14:02). Another factor to consider is the contact with few other groups who were training in parkour, and particularly one group formed in the same town. The practice was organized on a free basis: "It's really free. It's like ... parkour. Like you text your friends and then some of them might be doing homework and some of them would \{answer\} I'll be joining ..." (Interview - 0:18:39). This part emphasize the importance of enjoyment and friendship, which are, according to Nicolas, central to the parkour culture. After one year, Nicolas' group established contacts with more skilled practitioners: “... we started talking to international people who gave us some advice on how to train and how to warmup." (Interview - 0:19:39). Moreover, they attended to international events where it was possible to receive cues to learn new approaches.

After three years of parallel practice, when entering into higher education, Nicolas decided to continue only parkour: "I end up gymnastics because it was like always at the same hours every week so it was quite difficult to keep training and study. And, with parkour, I could just choose the hours when I wanted to train" (Interview - 0:09:29). This illustrates the transfer possibilities of parkour as an activity as you didn't need a gymnasium or coach. At the same period, with his friends, he started to teach twice a week in a sport facility. The activity grew up but remained amateur until the group was invited to teach at the local circus school. The classes were full immediately and some events were organized contributing to the promotion of the activities. It is noteworthy that he did not attend to competition: "I used to do competitions as a gymnast, which were really stressful. I hated it." (Interview - 0:31:15). After graduation (bachelor in $\mathrm{PE})$, Nicolas and his friend worked in the circus school: "I think we started with two classes 69 and two 9-12, then we did beginners, advanced, and adult classes ... From that moment, every year we were making more classes." (Interview - 0:29:52). 
As underlined in the retrospective study of Nicolas' story, we believe that one of the conditions to perform parkour is the availability of fundamental motor skills with a specific emphasis on acrobatic skills. As already mentioned, when he was a child, he practiced judo and was always trying to do some flips everywhere. “...Then my mum was like: "I really want you to stop trying those things on the grass or on the concrete. I want you to go to the gymnastics club". I start doing gymnastics and then I start doing parkour which is the same thing as gymnastics... (Interview - 0:20:13). His mother imposed him to begin gymnastics. Gymnastics is an ideal content to develop the fundamental motor skills such as climbing, rolling, jumping, gliding, swinging. Such basis and experience allows the learner to feel competent and to progress in parkour in a safe way. Support of others (friends, parents, other practitioners ...), availability of models (video clips, organization of events ...), and opportunities to develop structures (circus school) were other determining factors in this case. For current beginners, we consider that the development of teaching staff should contribute to the growing of the discipline. The latter has several advantages: a philosophy focused more on personal progression than on competition, a tradition of friendly support between participants, the reputation of being a cool activity, the low requirement of infrastructures. Alongside immersion in different environments another key element of learning to move in Parkour is learning to practice safely.

\section{Key elements of an effective/safe practice of Parkour}

At the beginning, Nicolas and his friends were imitating all online video clips that they could find without respecting safety requirements: “... we were copying all those clips but we didn't really know what we were doing. I think it was the most damaging year for the body until now ..." (Interview - 0:14:02). Parkour is often seen as a dangerous activity but there are always different ways to do something so safety can remain a priority. Moreover, Nicolas pointed out that the key factor is to show that the learner is competent: "What I think is really important in parkour is success." (Interview - 1:03:49). Competence will grow with practice. Our expert has parkour sessions twice a week and weekly conditioning activities.

Among the necessary competences that someone doing parkour needs, the number one is to be able to determine ones' capability: “... I can see it \{the move to do\} and judge myself, check if I'm able to do it and I can make a good judgement to know if I can try it in a safe way." (Interview - 1:11:47). A second determining competence is to try any movement in a controlled way, knowing exactly what to do if it does not work as expected.: "I can feel the jump but I know exactly what to do if I don't make the jump ..." (Interview - 1:12:30). A traceur should also be able to find a solution when facing an obstacle by using what has been learnt and by 
imagining new way of doing a movement: "If they start thinking for themselves, they can see a jump, know how this is maybe too difficult, and \{\} do it in that \{their $\}$ way." (Interview $1: 16: 26)$.

Feeling is important in parkour: "You do the warmup, you start jumping and there's always a moment you never know what it is, but there's always that moment when you feel warm and ready to do things you wanted to do." (Interview - 0:48:55). At the beginning of a session, the traceur tries small challenges then, little by little, increases the level of difficulty. In parallel, his level of readiness grows as well as his inner happiness: “... your mind starts to get more and more into parkour. The body gets more and more into parkour." (Interview - 0:50:10). These feelings tell that one is ready to do a specific movement: “.. you are like 'OK, I feel ready, I can do big jumps, I can do more challenging stuff"”' (Interview - 0:51:52).

It does not happen during each session. Sometimes, one feels ready to conquer one big jump as if the body and mind were under full control. Keeping calm is a priority: “... people think that we do things because we can feel adrenaline. That's not the case, we wait until the adrenaline slows down because adrenaline doesn't give you a lot of control ..." (Interview - 0:56:50). Taking a break, breath in and out are necessary. It helps to be highly focused and to know exactly what to do. One can feel the movement to be done; the confidence is maximum: "You feel completely ready to do certain jump and that's the best moment in parkour." (Interview 0:57:13). Such feelings can be also possible in beginners: "I think as soon as you know how to take decisions, as soon as you know how capable you are, I think you can feel the zone." (Interview-1:21:30). Getting in the zone could be linked to the challenges the traceur is facing: "When you have a challenge and it's hard enough and you have to work for." (Interview 1:23:57). It means that the zone is linked to the personal characteristics and that teachers should encourage their learners to find it. As parkour offers easy individual adaptations, any practitioner should find a way to enter into his/her zone. That could explain why parkour is more appreciated than many other sports requiring given levels of mastery before experiencing a sense of competence. If the learner decides alone which challenge he/she has to achieve, the intensity of the feeling will increase: "I think getting into the zone will be more intense of you created, if you found that challenge yourself." (Interview - 1:24:00). And when one achieved one challenge, it will be needed to practice again but training is the only way to realize a dream. Teaching the vision of parkour 
The vision of the parkour teaching is based on an open noncompetitive approach. Aiming for individual progression instead of competing against someone else: "It's important to grow as a person ... \{there is\} any competition so the whole atmosphere of the class is completely different .. It is not about winning or losing what creates a different atmosphere." (Interview - 0:25:08).

Within parkour, you need a training team that encourages and helps you to find and try out different tricks in different environments. Each teammate has another vision of the environment. All those visions and ideas together makes it a lot more interesting. Most parkour events exists of training together or workshops where someone is learning you certain parkour moves. There are some events with three kinds of competitions: a style, a speed and a skill competition. In the style competition, you show the jury in predefined space what you can do. The speed competition is like a race while the skill competition where the 'traceur' has to complete challenges. More recently, a new activity appeared: the chase tag. It is a pursuit race with obstacles in the play area.

For Nicolas, it is important to avoid that people compare themselves with others. On the contrary, when someone achieve a movement (vault, jump ...), it is expected that teammates praise the performance. Such philosophy encourages people to interact and train: "That's the reason why so many people train, just like encouraging each other and then try together." (Interview - 0:37:40). And reinforces teamwork: "So that makes it like so much more interesting to train together because you have so much more things that you can try because everybody has different parkour vision." (Interview - 0:38:40). It is like the DNA of the activity: "I think as soon as you're coming to a class, you can feel it and can see the way people train, give positive feedback to each other, and encourage each other." (Interview - 0:40:53).

Parkour sessions start with warming up and running. However, there are always funny tasks to avoid boredom. Fun is a key element in the development of learners' experience of parkour. Another principle is to propose mobility, para training, and conditioning but always connected to parkour tasks. Teaching parkour respects most of the conditions suggested to develop motivation (Viau, 2000). In addition, grouping of the learners in small groups lead by one teacher focusing on specific tasks corresponds to one of the TARGET framework dimensions (Ames, 1992). What teachers say and do is what creates a more task-involved or ego-involved climate. There are six factors that teachers have control over when they teach: (a) the task they ask their students to perform (T), (b) the amount of authority they allow their students to have (A), (c) the way rewards are given to students (R), (d) the way students are grouped (G), (e) how students are evaluated (E), and (f) the amount of time they allow students to complete a 
task (T). The acronym for each of these components is TARGET (Ames, 1992). The TARGET principles guide the approach in creating motivational climates being task-involving or egoinvolving. According to the interview, Nicolas aims for a task-involving climate during teaching: different tasks are given to the students, the latter can choose the task they want to practice, they have equal opportunities to receive rewards, they work in small groups, evaluation is self-referenced, and time to practice is flexible. As a part of each lesson allows participants choice, autonomy is also promoted, for example, where and how to train: "It's a big value because you can see how responsible, even a 6 year-old, can train. That's really cool to see." (Interview - 0:43:55). Open tasks where learners have to find their own solutions are also proposed systematically.

In summary, we can see that the whole teaching approach towards parkour applies all principles contributing to the development of a task involving climate. It is a nice illustration of the PAMIA (Cloes, 2017). Finally, during the cool down/stretching, the teachers show an inspiring video creating some need. Using new technologies can also increase motivation. In the same vein, when trying new movements, taking and sharing video can be helpful to other people as it can break a mental barrier by demonstrating that it is possible.

Another teaching principle is to adapt the tasks to the level of each learner to maintain them in the area of 'délicieuse incertitude' (Brunelle, Drouin, Godbout, \& Toussignant, 1988): "Everybody has a way to do it." (Interview - 1:04:40). In that way, Nicolas considers that nothing is wrong for the learner as far as it is safe or it respects the material. It means also that when learners find their own way to achieve a challenge, the teacher has to encourage them. is not a priority, mainly in children: "The main goal is to show to people what \{they\} are capable \{to do $\}$ with the body in a certain situation." (Interview - 1:25:40).

A final teaching approach important in parkour is for the teacher should go outside as often as possible as the diversity of the environment is more important: "I think training outside is so important because ... \{in\} a parkour gym, we can't recreate what is outside, how the structures are in a really strange shape." (Interview - 1:30:33).

\section{Conclusion: Generating Threshold concepts in and for parkour}

The discussion between an expert in parkour and two specialists in sport pedagogy has been an interesting experience as all of them had to involve them in a reflective practice aiming to better understand what is happening in the teaching-learning process in a new activity. Based on our 
experiences and the information collected through Nicolas' interview, we propose a series of threshold concepts that are crucial to the teaching but also experiencing Parkour,

1. Accept to try a movement perceived as a possible challenge;

2. Learn to control his/her movement to guarantee is/her safety (maintaining a low level of excitement, imagining the movement to be realized, identifying the possible risks);

3. Demonstrate supportive behaviors to his/her classmates;

4. Be able to show persistence;

5. Show autonomy and creativity to find way to overcome barriers;

6. Listen his/her body.

Teaching of Parkour

Develop a goal orientation on task mastery.

We pointed out that its success in parkour can be explained by characteristics specific to the fun culture, environmental influences but also by a series of pedagogical principles that are applied by the teachers to implement a task-involving climate. Parkour seems definitely a nice activity to develop the physical literacy in youth. A possible next step is to find ways in which these threshold concepts could now be nurtured within Physical Education.

\section{References}

Ames, C. (1992). Classrooms: goals, structures and student motivation. Journal of Educational Psychology, 84, 261-271.

Brunelle, J., Drouin, D., Godbout, P., \& Tousignant, M. (1988). La supervision de l'intervention en activité physique. Montréal, Canada: Gaëtan Morin Editeur.

Capel, S. \& Whitehead, M. (2004). Learning to teach PE in secondary school. A comparison to school experience. $2^{\mathrm{d}}$ ed. London, United Kingdom: Routledge Falmer.

Cloes, M. (2017). Preparing physically educated citizens in physical education. Expectations and practices. Retos, 31, 245-251. Available on:

http://recyt.fecyt.es/index.php/retos/article/view/53497/32304

Cloes, M., \& Roy, M. (2010). Le cheminement de l'approche écologique: du paradigme processus-produit au modèle heuristique du processus enseignement-apprentissage. In, M. Musard, M. Loquet \& G. Carlier (Eds.), Sciences de l'intervention en EPS et en sport : résultats de recherches et fondements théoriques (pp. 13-33). Paris, France: Editions Revue EP.S. Available on Internet : http://hdl.handle.net/2268/35774

Coolkens, R., Ward, P., Seghers, J., \& Iserbyt, P. (2018). Effects of 
Generalization of Engagement in Parkour from Physical Education to Recess on Physical Activity. Research Quarterly for Exercise and Sport, 89(4):429-439. DOI:

10.1080/02701367.2018.1521912

Coolkens, R., Van Oost, J., Vanhole, N., \& Iserbyt, P. (2018). Parkour primitives.

Praktijkboek. Oud-Turnhout, Belgium: Gompel \& Svacina.

De Martelaer, K., Seghers, J., Cardon, G., Haerens, L., De Boever, E., \& Cloes, M. (2014). Physical Education Stimulating a Healthy Lifestyle and Critical Sports Consumption in Belgium. In, M.-K. Chin \& C.R. Edginton (Eds.), Physical Education and Health Global Perspectives and Best Practice (pp. 43-56). Urbana, IL: Sagamore.

De Knop, P., Theeboom, M., Huts, K., De Martelaer, K., \& Cloes, M. (2005). The state of school physical education in Belgium. In, U. Pühse \& M. Gerber (Eds.), International comparison of Physical Education. Concepts. Problems. Prospects (pp. 104-131). Oxford: Meyer \& Meyer Sport.

Green, K. (2016, April). Can physical education be effective and, if so, how? Paper presented at the Consensus conference Children, youth and physical activity, Copenhagen, Denmark.

Hébert, G. (1974). La méthode naturelle. Education physique virile et morale. Tome 1 Doctrine et enseignements pratiques ( $7^{\mathrm{ème}}$ édition). Paris, France : Vuibert.

Iserbyt, P. \& Coolkens, R. (2019). Physical Education Teacher Education in Flanders (Belgium). In, A. MacPhail, D. Tannehill \& Z. Avsar (Eds), European Physical Education Teacher Educaion Practices : Initial, Induction, and Professional Development (pp. 25-26). Maidenhead, United Kingdom: Meyer \& Meyer Sports.

Loret, A. (1995). Génération Glisse. Dans l'eau, l'air, la neige...la révolution du sport des "années fun". Paris, France: Autrement.

Sallis, J., Cervero, R., Ascher, W., Henderson, K., Kraft, M., \& Kerr, J. (2006). An ecological approach to creating active living communities. Annual Review of Public Health, 27, 297-322.

Viau, R. (2000). Des conditions à respecter pour susciter la motivation des élèves. Correspondance. 5(3), 2-4. 


\section{Appendix 1 Guideline Interview Nicolas Vanhole Expert and teacher in Parkour}

\section{Questions for expert teacher in parkour}

Clarify stage

\section{Background information}

1. How old are you?

2. What did you study?

3. How long have you been teaching parkour?

4. Why did you become a teacher in parkour?

5. For how many hours per week are you teaching parkour?

6. What age group do you teach?

7. What skill level do you teach?

8. Which group is the most difficult to teach parkour and why?

Information about teaching parkour

- How do you plan/prepare for teaching parkour? Do you have a written preparation and if yes, how does it look like?

- How do you develop content in parkour?

- How important is your own skill mastery for teaching parkour?

- How do you assess children's parkour performance?

- Do you define parkour goals for each lesson, each time period or do you define no goals at all?

- Is there anything else besides skill competency that you want children to learn in parkour?

- How do you create fun for children?

- How does a quality lesson look like?

- Do you reflect on your teaching? If so, how?

1. What makes you an expert teacher in parkour?

2. What are in your opinion the essential skills to teach parkour?

a. How much time do you need to develop these skills?

b. What do you need, to develop those skills?

c. Are these skills different according to the group (gender, skill level, age) you teach?

3. Do you think that as a teacher in parkour it is important to practice parkour by yourself?

a. Instead of yes, on which level you should participate to become an expert teacher in parkour?

4. How do you teach parkour (teacher-led, student-led, heterogeneous groups...)?

\section{Questions for parkour practitioner}

\section{Background information}

1. When did you start doing parkour?

2. Why did you start with it?

3. For how many hours a week are you doing parkour?

\section{Information about doing parkour}

1. What makes you an expert in doing parkour? 
2. What are according to your opinion the most necessary skills (fundamental components) to do parkour at an expert level?

a. How much time do you need to develop those skills?

b. What do you need/ or how can you, develop those skills?

c. Are those skills different for beginners?

3. Are there components necessary before you can make progression?

5. If you are ' in the zone' what do you hear, see, feel? I read a text of you on Instagram where you posted: once you're in that moment and you feel it....

6. When can you experience fun while doing parkour?

7. What is learned in parkour (cognitive, psychomotor and affective)? 